\title{
TUJUAN DAN KRITERIA PERENCANAAN ASUHAN KEPERAWATAN DI RUMAH SAKIT
}

Ade Sulistya Lubis/181101121

\author{
adesulistyalubis@gmail.com
}

\begin{abstract}
Abstrak
Latar belakang:Perencanaan adalah merupakan bagian dari fase pengorganisasian dalam proses keperawatan sebagai pedoman untuk mengarahkan tindakan keperawatan dalam usaha membantu, meringankan, memecahkan masalah. Tujuan: Untuk mengetahui apa tujuan dan kriteria perencanaan asuhan keperawatan di rumah sakit. Metode: menggunakan metode tersearch dan analisis dari berbagai sumber seperti buku teks, buku referensi jurnal, e-book, dan juga membandingkan beberapa jurnal yang berhubungan dengan tujuan dan kriteria perencanaan asuhan keperawatan di rumah sakit. Hasil: Tujuan perencanaan intervensi keperawatan dan aktivitas keperawatan untuk mengurangi, menghilangkan, dan mencegah masalah keperawatan klien.Kesimpulan: Kriteria proses perawatan membuat rencana tindakan asuhan keperawatan untuk mengatasi masalah dan meningkatkan kesehatan meliputi perencanaan terdiri atas prioritas, tujuan dan rencana tindakan keperawatan, bekerjasama dengan klien dalam menyusun rencana tindakan keperawatan, perencanaan bersifat individual sesuai dengan kondisi atau kebutuhan klien, mendokumentasikan rencana keperawatan
\end{abstract}

Kata kunci: Tujuan, Perencanaan, Asuhan Keperawatan

Background: Planning is part of the organizing phase in the nursing process as a guide to directing nursing actions in an effort to help, alleviate, solve problems. Objective: To find out what are the goals and criteria for planning nursing care in a hospital. Method: using the search method and analysis from various sources such as textbooks, journal reference books, e-books, and also comparing several journals related to the objectives and criteria for planning nursing care at the hospital. Results: The purpose of planning nursing interventions and nursing activities to reduce, eliminate, and prevent client nursing problems. Conclusion: Criteria for the care process to create a plan for nursing care actions to overcome problems and improve health include planning consisting of priorities, goals and action plans for nursing, in collaboration with client in preparing a nursing action plan, planning is individualized according to the client's condition or needs, documenting the nursing plan

Keywords: Purpose, Planning, Nursing Care 
PENDAHULUAN

\section{LATAR BELAKANG}

Perencanaan

Keperawatan

Merupakan suatu proses penyusunan berbagai intervensi keperawatan yang dibutuhkan untuk mencegah, menurunkan, atau mengurangi masalah-masalah klien. Perencanaan ini merupakan langkah ketiga dalam membuat suatu proses keperawatan.

Langkah dalam tahap perencanaan ini dilakukan setelah menentukan tujuan dan kriteria hasil yang diharapkan dengan menentukan rencana tindakan apa yang akan dilaksanakan dalam mengatasi masalah klien. Dalam membuat rencana tindakan perawat harus mengetahui juga tentang instruksi atau perintah tentang tindakan keperawatan apa yang akan dilakukan dari perawat primer (pembuat asuhan keperawatan primer).

Untuk memudahkan dalam menentukan rencana tindakan, maka ada beberapa persyaratan dalam menuliskan rencana tindakan diantaranya harus terdapat unsur tanggal, kata kerja yang dapat diukur yang dapat dilihat, dirasa dan didengar, adanya subjek, hasil, target tanggal dan tanda tangan perawat.
Dalam penentuan rencana tindakan terdapat beberapa instruksi tindakan keperawatan yang merupakan suatu bentuk tindakan yang menunjukan perawatan dan pengobatan khusus, dimana perawat mempunyai kewenangan untuk melakukan tindakan pada pasien tertentu. Perawatan dan pengobatan dirancang untuk membantu pencapaian satu atau lebih dari tujuan perawatan sehingga dapat mengurangi, mencegah atau menghilangkan dari masalah pasien. (A. Aziz Alimul Hidayat, pengantar konsep dasar keperawatan)

Tujuan perencanaan intervensi keperawatan dan aktivitas keperawatan untuk mengurangi, menghilangkan, dan mencegah masalah keperawatan klien. Kriteria proses perawatan membuat rencana tindakan asuhan keperawatan untuk mengatasi masalah dan meningkatkan kesehatan meliputi perencanaan terdiri atas prioritas, tujuan dan rencana tindakan keperawatan, bekerjasama dengan klien dalam menyusun rencana tindakan keperawatan, perencanaan bersifat individual sesuai dengan kondisi atau kebutuhan klien, 
mendokumentasikan rencana keperawatan (Nursalam,2007).

\section{TUJUAN}

Tujuan pembandigan dari beberapa jurnal dan sumber lainnya agar dapat mengetahui apa tujuan dan kriteria perencanaan asuhan keperawatan di rumah sakit

\section{METODE}

Jurnal ini menggunakan metode tersearch dan analisis dari berbagai sumber seperti buku teks, buku referensi jurnal, ebook, dan juga membandingkan beberapa jurnal yang berhubungan dengan tujuan dan kriteria perencanaan asuhan keperawatan di rumah sakit.

Dari analisi berbagai sumber digunakan Untuk mengetahui tujuan dan kriteria perencanaan asuhan keperawatan di rumah sakit. Penulisan jurnal ini dimulai pada tanggal 10 november 2019. Pengolahan jurnal dilakukan dengan metode membandingkan beberapa jurnal yang berhubungan dengan tujuan dan kriteria perencanaan asuhan keperawatan di rumah sakit.

\section{HASIL}

Penelitian ini menunjukkan perencanaan dan implementasi juga belum mencapai standar yang ditetapkan Depkes RI. Implementasi merupakan tindakan atau aplikasi dari rencana asuhan keperawatan untuk mencapai tujuan yang diharapkan. Dalam melakukan tindakan sesuai dengan rencana keperawatan maka diperlukan jumlah tenaga perawat yang cukup, pengetahuan dan keterampilan yang baik. Tenaga perawat yang paling dibutuhkan ketika jumlah klien meningkat dan kondisi klien menurun (Potter \& Perry, 2005).

Hal ini merupakan komponen manajemen keperawatan yang perlu diperhatikan oleh manajer keperawatan (Gillies, 2005). Hal ini kembali kepada peran manajer perawat untuk memperhatikan jumlah tenaga kerja atau perawat agar sebanding dengan beban kerja perawat, pengetahuan dan kemampuan perawat perawat juga ditingkatkan melalui pelatihan dan pendidikan lanjut.

$$
\text { Tujuan rencana asuhan }
$$

keperawatan yaitu tujuan administrasi meliputi mengidentifikasi fokus keperawatan individu atau keluarga, 
membedakan tanggung jawab perawat dengan profesi kesehatan lainnya, menyusun kriteria guna pengulangan asuhan keperawatan dan evaluasi, keberhasilan asuhan keperawatan, menyediakan kriteria klasifikasi klien, sedangkan tujuan klinik meliputi suatu pedoman dalam penulisan, mengkomunikasikan asuhan keperawatan yang akan diimplememtasikan dengan perawat lain seperti apa yang akan diajarkan, apa yang harus diobservasi, apa yang akan dilakukan.

Menyusun kriteria hasil (outcome) guna pengulangan asuhan keperawatan dan evaluasi keberhasilan asuhan keperawatan, rencana intervensi yang spesifik dan langsung bagi perawat untuk melaksanakan intervensi kepada klien dan keluarganya (Cafenito,2006).

\section{PEMBAHASAN}

Perencanaan merupakan suatu petunjuk tertulis yang menggambarkan secara tepat rencana tindakan keperawatan yang dilakukan terhadap klien sesuai dengan kebutuhannya berdasarkan diagnosis keperawatan.
Rencana asuhan keperawatan adalah petunjuk tertulis yang menggambarkan secara tepat mengenai rencana tindakan yang dilakukan terhadap klien sesuai dengan kebutuhannya berdasarkan diagnosis keperawatan.

\section{Tujuan Rencana Asuhan Keperawatan}

\section{Tujuan umum:}

1. Sebagai alat komunikasi antara sesama anggota perawatan dan antar tim kesehatan lainnya

2. Untuk meningkatkan kesinambungan asuhan keperawatan terhadap klien.

3. Mendokumentasikan proses dan kriteria hasil asuhan keperawatan yang akan dicapai.

\section{Tujuan Administratif :}

1. Mengidentifikasi fokus keperawatan kepada klien atau kelompok

2. Membedakan tanggung jawab perawat dengan profesi kesehatan lainnya

3. Menyediakan suatu kriteria guna pengulangan dan evaluasi keperawatan 
4. Menyediakan kriteria klasifikasi klien.

Tujuan kilen dan tujuan keperawatan adalah standar atau ukuran yang digunakan untuk mengevaluasi kemajuan klien atau keterampilan perawat. Menurut Alfaro(1994), tujuan klien merupakan pernyataan yang menjelaskan suatu perilaku klien, keluarga, atau kelompok yang dapat diukur setelah intervensi keperawatan diberikan.

Tujuan keperawatan adalah pernyataan yang menjelaskan suatu tindaka yang dapat diukur berdasarkan kemampuan dan kewenangan perawat. Kriteria hasil untuk diagnosa keperawatan mewakili status kesehatan klien yang dapat dicapai atau dipertahankan melalui rencana tindakan yang mandiri, sehingga dapat membedakan antara diagnosa keperawatan dan masalah kolaburatif. MenurutGordon(1994), komponen kriteria hasil yang penting dalam kriteria hasil adalah apakah intervensi keperawatan dapat dicapai

\section{Karakteristik rencana tindakan keperawatan:}

a. Konsisten dengan rencana tindakan.

b. Berdasarkan prinsip-prinsip ilmiah(rasional).

c. Berdasarkan situasi individu klien.

d. Digunakan untuk menciptakan suatu situasi yang aman dan teraupetik.

e. Menciptakan suatu situasi pengajaran.

f. Menunggu saran yang sesuai(ANA,1973).

Perencanaan keperawatan disusun berdasarkan diagnosa keperawatan yang meliputi beberapa point seperti :

- Prioritas asuhan keperawatan dengan kriteria : Spesifik, bisa diukur, bisa dicapai,realistik, ada batas waktu.

- Tujuan asuhan keperawatan dengan kriteria : spesifik, bisa diukur, bisa dicapai, realistik,ada batas waktu.

- Rencana tindakan dengan kriteria yang disusun berdasarkan tujuan asuhan keperawatan, melibatkan paien/keluarga, 
mempertimbangkan latar belakang

budaya

pasien/keluarga,menentukan

alternative tindakan yang tepat,

mempertimbangkan

kebijaksaandan peraturan yang ber laku, lingkungan, sumberdaya, dan fasilitas yang ada, menjamin rasa aman dan nyaman bagi pasien, kalimat intruksi, ringkas, tegas dengan bahasanya mudah dimengerti

\section{PENUTUPAN}

\section{KESIMPULAN}

Perencanaan adalah merupakan bagian dari fase pengorganisasian dalam proses keperawatan sebagai pedoman untuk mengarahkan tindakan keperawatan dalam usaha membantu, meringankan, memecahkan masalah atau untuk memenuhi kebutuhan klien.Suatu perencanaan yang tertulis dengan baik akan memberi petunjuk dan arti pada asuhan keperawatan karena perencanaan adalah sumber informasi bagi semua yang terlibat dalam asuhan keperawatan klien.

\section{SARAN}

Dalam membuat rencana tindakan perawat harus mengetahui tujuan dan kriteria perencanaan kepewatan agar perawat dapat melakukan tindakan yang tepat dan menciptakan suatu situasi yang aman dan teraupetik

\section{REFERENSI}

Allen, V. C. (1998). Memahami Proses

Keperawatan Dengan

Pendekatan Latihan. Jakarta:

EGC.

Asmadi. (2008). Konsep Dasar

Keperawatan. Jakarta: EGC

Asmuji. 2012. Manajemen Keperawatan Konsep dan Aplikasi. Jogjakarta: Ar-Ruzz Media.

Haryanto. 2007. Konsep Dasar Keperawatan dengan Pemetaan Konsep. Jakarta : Salemba medika.

Kemenkes RI. (2015). Profil Kesehatan Indonesia Tahun 2014. Jakarta..

Carpenito, L.J., 1999. Rencana Asuhan dan Dokumentasi Keperawatan, Diagnosa Keperawatan dan Masalah Kolaboratif Edisi 2. Jakarta: EGC 
Doengos, M.E., (2000), Rencana Asuhan

Keperawatan : Pedoman Untuk

Perencanaan Pendokumentasian

Perawatan Pasien Ed. 3

Kemenkes RI. (2015). Profil Kesehatan

Indonesia Tahun 2014. Jakarta..

Kozier, Barbara. (2010). Buku Ajar Fundamental Keperawatan; Konsep, Proses dan Praktik edisi 7 Volume. Jakarta: EGC.

Simamora, R. H. (2019). Menjadi Perawat yang: CIH'HUY. Surakarta: Kekata Publisher.

Simamora, Roymond H. 2010. Komunikasi dalam Keperawatan, Ed 1 hal 210. Jember: Univesity Press.

Simamora, Roymond H. Dokumentasi Proses Keperawatan, `Ed 1 hal 144. Jember: University Press.

Simamora, Roymond H. 2008. Peran Manajer dalam Pembinaan Etika Perawat Pelakasanaan dalam Peningkatan Kualitas Pelayanan Asuhan Keperawatan: Jurnal IKESMA, Ed 4, 2.

Potter \& Perry, (2005). Buku Ajar Fundamental Keperawatan:
Konsep, Proses, dan Praktik.

Edisi 4. Vol 1. Jakarta: EGC.

Potter \& Perry. (2009). Fundamental of Nursing. 7 th Ed. St Louis Missouri: Elseiver

Perry, A. G., \& Potter, P. A. (2009). Potter and perry's fundamentals of nursing Australian version. (J. Crips \& C. Taylor, Eds.) (3 ${ }^{\text {rd }}$ ed). Australian : mosby Elsevier Australia.

Potter, P.A.,\& Perry, G.A. (2010). Fundamental of nursing (Volume 2, 7th Ed.). ST. Louis: Mosby Year Book.

Potter, P. A., \& Perry, A. G., (2013). Fundamentals of nursing. ( $\left.8^{\text {th }} \mathrm{ed}\right)$. Elsevier. 